\title{
DESIGN E-DESKEL SOFTWARE AS A SERVICE FOR POTENTIAL AND ADMINISTRATION MANAGEMENT OF VILLAGE
}

\author{
Hermin Arrang', Matius Sau², Mingsep Sampebua ${ }^{3}$ \\ ${ }^{1}$ Information Engineering, Universitas Kristen Indonesia Paulus, Makassar, Indonesia \\ ${ }^{2}$ Electrical Engineering, Universitas Kristen Indonesia Paulus, Makassar, Indonesia \\ ${ }^{3}$ Faculty of mathematics and science, university of Cendrawasih, Indonesia
}

\begin{abstract}
As the smallest part of the system of administrative governance in Indonesia, the village still has a conventional government in terms of data processing and delivery of information to the village. That the system of government and public services are clean, fair, and transparent is a challenge that must be addressed by central government agencies to ensure that regional and village government is carrying out its functions. The advances of information and communication technology so rapidly open up opportunities for community and village government, including online information access, management and administrative services, and information about the potential of the village. The purpose of this research is to design and implement a cloud EDesKel program to address the problems faced by residents and village officials. E-DesKel is appropriate technology for the task; it performs a public service by implementing cloud computing in the form of Software as a Service (SaaS) to achieve content management and Infrastructure as a Service (IaaS) as a storage medium. E-DesKel provides facilities for the village administration and public services, reducing operating costs and delivering information quickly and accurately. The software development of cloud E-DesKel, using the linear sequential method, includes four phases: analysis, design, coding, and testing.
\end{abstract}

Keywords: Cloud E-Deskel, Information Systems, Village Administration, Village Potential, SaaS.

\section{INTRODUCTION}

Along with the development of information and communication technology, human daily activities in a variety of sectors are undergoing change. So also are the public service sector conducted by central and local government changing, as well as government at the level of villages. A village, based on Law No. 32 of 2004 on Regional Government, is the unity of the legal community who have jurisdictional boundaries. The authority to regulate and manage the interests of the local community, based on origins and local customs, is recognized and established in the system of national government and is located in the district or city. The development of information and communication technologies has given rise to a model of public service that is accomplished through eGovernment and can be accessed online. Government services, which tend to be bureaucratic and rigidly enforced, will be eliminated through the use of e-Government to be more flexible and user satisfaction oriented.

Realizing the benefits of e-Government, the Indonesian government issued a policy on the development of an eGovernment strategy. According to Presidential Decree No. $3 / 2003$, the development of e-government is intended to develop the implementation of an electronic-based governance in order to improve the quality of public services effectively and efficiently. This will be accomplished through the development of e-government to restructure management systems and work processes within government. According to Curtin. G (2007), E-Government is made up of three things: e-Administration, e-Services, and
E-Participation. E-Administration refers to mechanisms of the processes of administration and bureaucracy, and the transparency of the government that can be accessed and monitored. E-Services are online services meant to establish a synergistic relationship from government-to-citizen, government-to-business, government-to-government, and government-to-employee. Through a synergistic relationship, public services will be more organized, purposeful, and planned, and actual results will be obtained in accordance with the expectations of each party. EParticipation is an effort to introduce opportunities for the community to more fully participate in the implementation of government efforts.

As the spearhead of the system of administrative governance in Indonesia, villages must be able to keep up with technology and continuously improve administration performance in managing data and delivering information online. Currently, for villages in the North Toraja Regency, information such as system administration and delivery of services is still recorded conventionally, such as recording and data storage in the register books, the manufacture of application letters using the Microsoft Word application, and complex report generation requiring one to find and examine the data archives. The information is difficult to access as a result. The manual work culture that once spurred the village officials and community was left behind in the mastery of information and communication technologies that could not be avoided in the era of globalization. 
The problems mentioned above resulted in difficulties for the government in managing the data for village administration, slow service to the community, and difficulties delivering information about the village and about indicators of investment opportunities. Therefore, the villages need a system of administration named E-Deskel. E-DesKel presents Cloud Computing as a paradigm that enables the community and village officials to access information electronically using a computer or mobile phone connected through the Internet. The concept of cloud computing is best explained by describing the cloud computing architecture. Cloud computing provides a set of services and can be represented as a layered architecture. There are three architectural layers: Software as a Service (SaaS), Platform as a Service (PaaS) and Infrastructure as a Service (IaaS) (Kostandina Veljanovska, Violeta Zdravevska 2013). E-DesKel is Software as a Service (SaaS), on-demand service with rapid elasticity, broad network access, resource pooling, and measured service.

E-DesKel is a public service that implements cloud computing, in the form of SaaS services as a Content Management System (CMS) and of IaaS as a data storage medium. Features offered by the E-DesKel are the village administrative data processing and providing information about the investment potential of the village. Implementation of E-DesKel in the North Toraja Regency can present online, up-to-date information, reduce the occurrence of human error, manage time efficiently, reduce the operating costs of the village, and improve the administrative management of the village. Data and information are integrated and this village information is used as a basis to create development policies that are more focused and targeted, and to be able to bring in investors who can ultimately improve the welfare of the society. This study focuses on the design of the E-DesKel system that can be utilized in the form of software-based E-Deskel. The EDesKel modeling system uses a structured approach that includes context diagrams, DFD (data flow diagrams), and relationships between tables.

\section{METHODOLOGY}

\subsection{Method of Data Collection}

a. The literature data was collected by studying references in the form of documents and files, legislation, books, research journals, proceedings, and other forms related to e-government, village administration, and the potential of the village.

b. The observation method is a method of research involving direct observation. Village officials in the North Toraja district associated with the administration of village and rural potential were observed directly. It is very necessary to analyze and evaluate the current system and provide a solution by developing a system of web-based E-Deskel.

c. The interview method is a conversation between a researcher and an informant. Interviews were conducted directly with village officials, the public, and relevant agencies that had insight on the village administration system and the potential of the village.

\subsection{Development Method of E-DesKel}

The development of the E-DesKel cloud system, using the linear sequential method (Roger S. Pressman, 2002), includes four phases: analysis, design, coding, and testing.

a. Analysis: Phase analysis is the decomposition of system administration for the village as a whole into simpler parts in order to identify and evaluate the problems, opportunities, barriers, and needs of the village. At this stage of data analysis, the user needs to gain a complete understanding of the processes of the administration village or sub-district, the mechanism of application letters from the villagers, the delivery of information to the public, and then report to the Board of the district level Village Community Empowerment (BPMD). At this stage, the system has determined the E-DesKel requirements, which are described by the flow map village administration system that runs today based on the specification process of E-DesKel.

b. Design: The most important part of the design phase is translating stage analysis results into a form that is easily understood by the user. Based on the analysis of user requirements, design modeling is performed to capture and explain the needs of the user as well as the transformation of the results of the analysis in the form of modeling diagrams. The E-DesKel system is modeled using structured modeling that includes context diagrams, data flow diagrams (DFD), and design relationships between tables in the E-DesKel database.

c. Coding: After the translation stage, a design model is created in the form of program code (software applications E-DesKel) using the programming language PHP, the CodeIgniter framework, and MySQL databases.

d. Testing: The E-DesKel application is tested in order to fix any errors that might occur and to make changes or additions in accordance with user demand.

\section{RESULTS AND DISCUSSIONS}

\subsection{Results}

The results of the research on several villages in the district of North Toraja, concerning the system administration and delivery of information services to the community, are still conventional. Implementation of the system resulted in difficulties for the government in managing administrative data, providing timely administrative services to the community, and delivering information about the data potential of the village and the indicators of investment opportunities. By looking at the current problems and the existing working system, the proposed solution is to build a cloud system for villages to access service information; this program would be named E-Deskel.

E-DesKel will provide application services, systems maintenance, and infrastructure and centralized data storage in the cloud server. E-DesKel is a public service that 
implements cloud computing services in the form of Software as a Service (SaaS) as a Content Management System (CMS) and Infrastructure as a Service (IaaS) as a data storage medium. The CMS E-DesKel can create uniformity in data processing features, information, and communication for villages. E-DesKel contains the features and modules that are ready-made, uniform, on demand, and able to process information, in addition to being useful for and accessible to many in the village. This service will provide a lot of advantages both for service providers and users, and it is able to overcome the problems faced by each village government and its people.

The design of the E-DesKel system uses a structured approach that includes context diagrams, DFD (data flow diagrams), and a model of a cloud E-Deskel. The context diagram is a fundamental model of the system that represents all elements in E-DesKel as a single bubble, with input and output data indicated by the arrows entering and leaving the system. Figure 1 shows the context diagram for the E-DesKel system. The Data Flow Diagrams (DFD) EDesKel system is used to describe the system as a network of processes in relation to one another through the data flow. Data Flow Diagrams (DFD) consists of external entities, data flows, processes, and data storage. Figure 2 shows the Data Flow Diagrams (DFD) system.

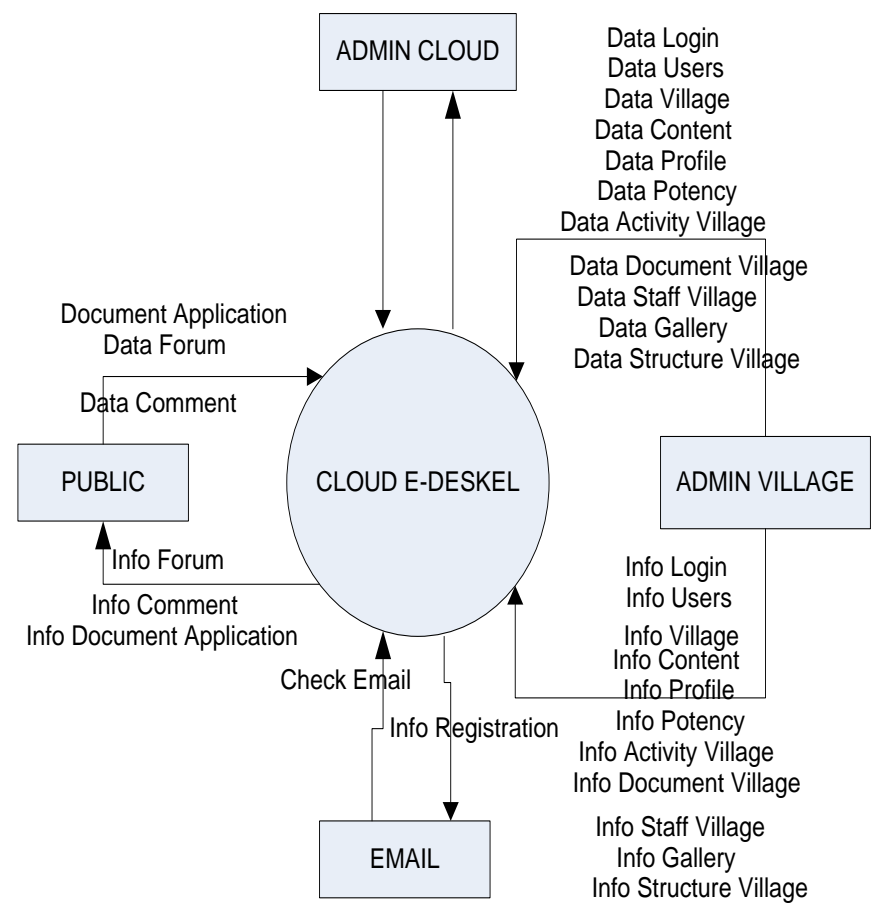

Figure 1: Diagram context of cloud E-Deskel

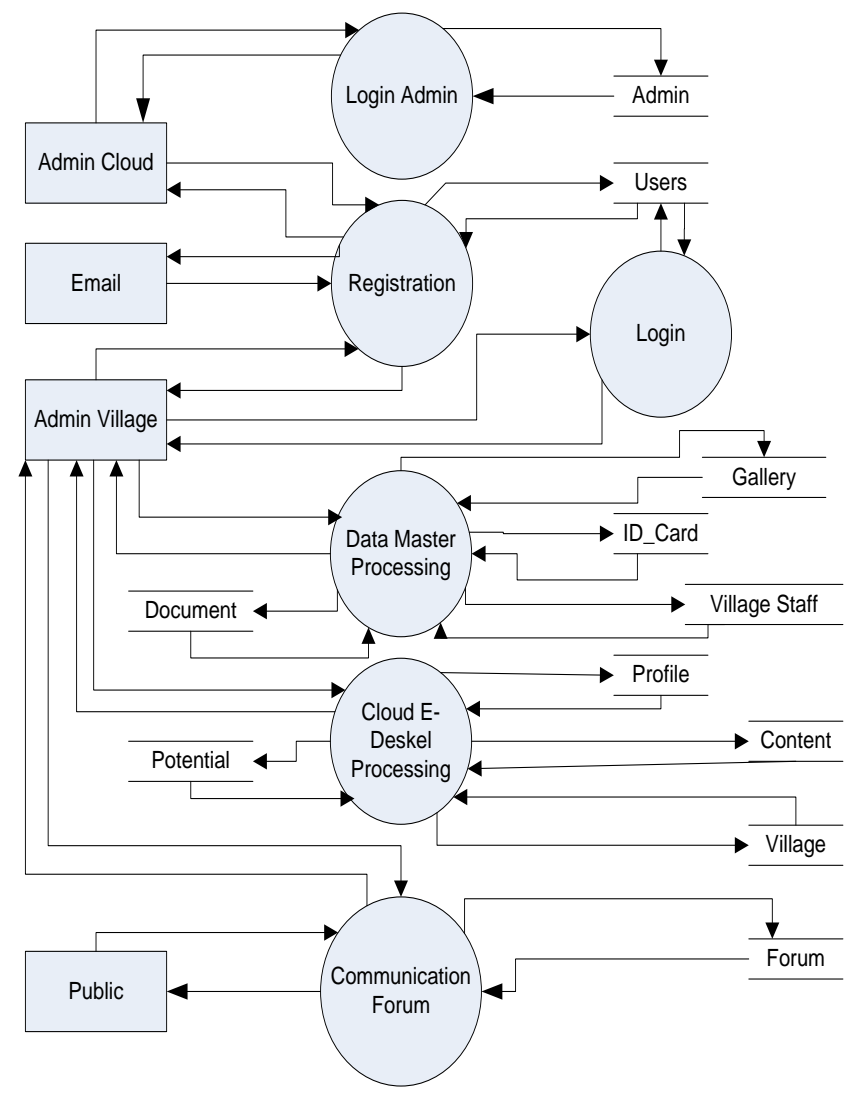

Figure 2: Data flow diagram of E-Deskel

The E-DesKel Cloud is a model of a web based application service for administration management and information access so that village government does not need to provide server, storage, application, maintenance, software, and IT experts. Each village government could simply subscribe by selecting the service package needed. Administrative staff will fill and manage the content on the template provided by E-Deskel. E-DesKel can provide online services so that the rural information delivery process becomes faster, easier, and cheaper, and creates an integrated information network. Below, Figure 3 shows a model of the E-DesKel cloud. 


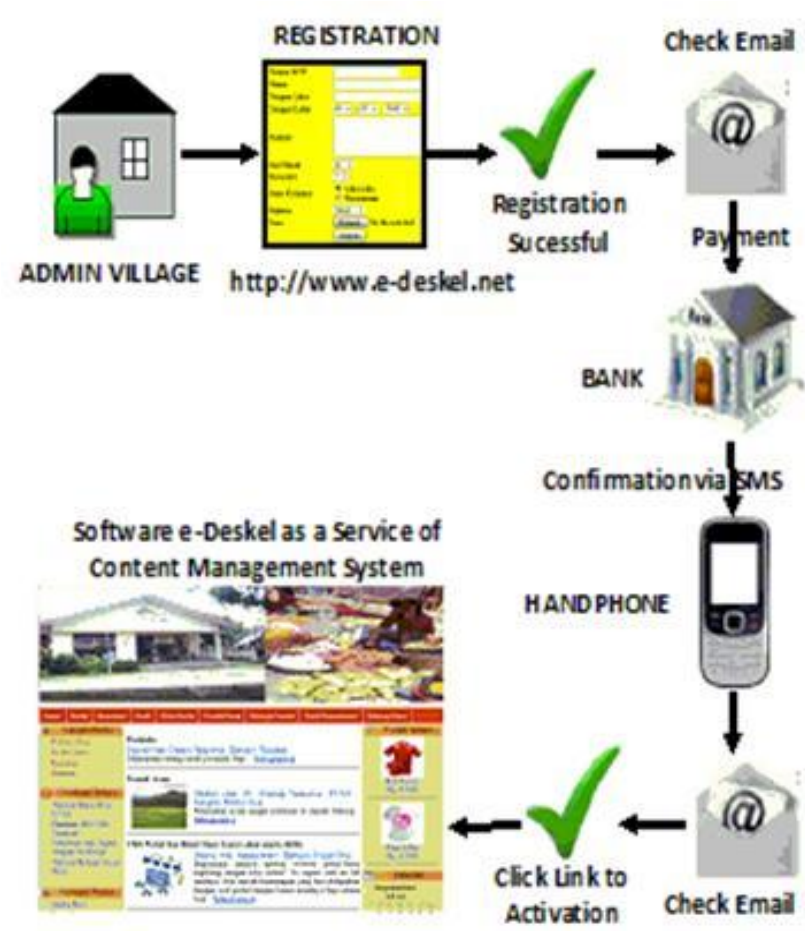

Figure 3: Model of cloud E-Deskel

\subsection{Discussions}

The E-DesKel system that implements cloud computing has both a front-end and a back-end aspect. Both are connected via a network (internet) with a cloud system. The front-end is located on the side of the user, such as village government A, village government $\mathrm{B}$, or village government $\mathrm{C}$, as well as within the population. The front-end includes a computer network user and village sites that have been processed for visitors, and it requires a web browser to access government services such as CMS. Meanwhile, at the back end of the system is part of the cloud server that acts as Infrastructure as a Service (IaaS), which can be used for data storage (storage) in villages, as well as an application of Software as a Service (SaaS) that can be used by many villages. The overall architecture for creating cloud services E-DesKel is as follows: service architecture Software as a Service is based on the needs and benefits that can be met and achieved by the software, once the software is installed and running in the cloud. SaaS is able to replace the traditional software still widely used by computer users because of their ability to keep costs down for labor and for the hardware requirements. Software as a Service services are provided in the E-Village in the form of a Content Management System (CMS) with a uniform feature to be used in a lot of villages, both in terms of information processing and administrative applications that are in the village.

The advantages of the cloud computing system, namely the E-Deskel, are as follows:

a. The system is built on top of a computer cluster that is diverse and dispersed, interconnected through the Internet to form a distributed system. It has been shown to save financial resources for procurement, maintenance, and system upgrades.

b. The system provides a platform that is elastic, which is able to adapt to the processing resources, memory, and storage needs of the E-DesKel application.

c. Physical resources (computers) in the cloud infrastructure can be placed in their desired locations, such as in the office BPMD North Toraja Regency. A virtual machine on a computer can be used as a host for the specific applications of each village. The local government can take advantage of these cloud applications seamlessly to provide E-Government services with value-rich local context (social, cultural, economic). The traditional approach, in contrast, is to put the application on a web server hosting provider.

d. Computing resources (virtual machines) are used and released in accordance with the user demand cloud (ondemand) and auto-service. The cloud applications from the user can be placed on a virtual machine automatically, without any personal interaction with the cloud system manager. This means there is no direct interaction between the cloud user build cloud infrastructures.

e. Virtual infrastructure and services available for the EGovernment in the cloud system can be accessed by the internet protocol mechanisms (http, ftp, p2p) using a standard computer. The traditional system (clientserver), on the other hand, depends on a platform provided by the web hosting provider.

f. Availability and service activities and resources are controlled and monitored by the cloud manager, which is necessary for monitoring, access control, resource optimization, and capacity planning. The implementation of the E-DesKel cloud on the BPMD North Toraja Regency can provide benefits that improve the quality of public services; improve process transparency and accountability among government administrators; reduce transaction costs, communications, and interactions that occur in the process of governance and service to the community; and create a working culture and community of higher quality information to the smart village.

\section{CONCLUSION}

From the results of the design research for the application of E-DesKel administration and the potential for web-based village in North Toraja Regency, it can be concluded as follows:

a. Development of the E-DesKel system in the North Toraja Regency can form an integrated database of village government, village administrative services and quality management, information potential of the village, and the data supporting investment opportunities, for which data is sourced directly from some of the villages. The data contained in the database can be used to support policy development and improvement of rural welfare.

b. The web based system E-DesKel is a medium sized, upto-date program and can be accessed online at any time by the villages. 
c. Creating a work culture based on information technology may not be avoided by the smart village.

\section{REFERENCES}

[1] Ali Rokhman (2008). Government Customer Service Through E-Government: The $2^{\text {nd }}$ National Conference UKWMS Surabaya, 6 September 2008.

[2] Curtin, GG, 2007, The E-government, Manuscript accepted for publication by Sage Publications in the "Encyclopedia of Political Communication" Egovernance-April 2007, URLhttp: //www.usc.edu/schools/sppd/bedrosian/private/ docs/ encyclopedia of_political_communications.pdf.

[3] Eko Widianto D., (2011). Towards E-Government Systems Integrated and Reliable Cloud- Computing Based, Journal of Computer Systems Vol. 1, 1, ISSN: 2087-4685.

[4] Presidential Instruction No. 3 In 2003, The National Policy and Strategy Development of e-Government.

[5] Kostandina Veljanovska, Violeta Zdravevska (2013). E-Government Based on Cloud Computing, International Journal of Emerging Trends in Computing and Information Sciences, Vol. 4, No. 4 April 2013, ISSN 2079-8407.

[6] Roger S. Pressman (1997). Software Engineering: A Practitioner's Approach, McGraw-Hill Companies, Inc.

\section{BIOGRAPHIES}

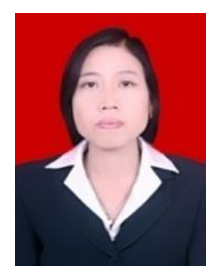

Hermin Arrang received the master of Electrical engineering degree in Information and Telecommunication Engineering at Hasanuddin University. She is currently lecturer in Information Engineering Department at Universitas Kristen Indonesia Paulus (UKI Paulus), Makassar-Indonesia.

Email : hermin_arrang@yahoo.co.id,

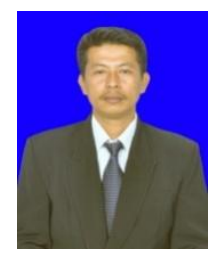

Matius Sau received the master of Electrical Engineering degree in Power System field at the Bandung Institute of Technology. He is currently lecturer in electrical engineering Department at Universitas Kristen Indonesia Paulus (UKI Paulus), Makassar-Indonesia.

Email : sau_tpsdp@yahoo.com,

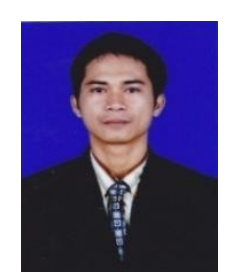

Mingsep Sampebua received the Doctor of Electrical Engineering degree in Information Technology at Gadjah Mada University. $\mathrm{He}$ is currently lecturer in Faculty of mathematics and science university of Cendrawasih, JayapuraIndonesia

Email : mingsepugm@yahoo.com 